\title{
Case Study on Accelerated Hypertension With Grade IV Retinopathy And Nephropathy
}

\author{
Dr. Nandita Basak \\ Junior Resident Doctor, Pradyumanabal Memorial Hospital, Kalinga Institute Of Medical Sciences \\ ,Bhubhaneswar-751024,INDIA
}

\begin{abstract}
: 42yr old patient was admitted in hospital with complaints of blurred vision swelling of feet and generalized weakness for more than 2 months. General examination revealed that his BP was 210/110mmHg with pulse 104/min, having bilateral pitting edema. He is a known case of hypertension, and is now being diagnosed as accelerated hypertension and is treated for it.
\end{abstract}

\section{Introduction}

Hypertensive emergencies include both accelerated hypertension and malignant hypertension. In both cases a recent increase in blood pressure to very high levels ( $\geq 180 \mathrm{~mm} \mathrm{Hg}$ systolic and $\geq 110 \mathrm{~mm} \mathrm{Hg}$ diastolic) results in target organ damage - usually seen as neurological (e.g., encephalopathy), cardiovascular or renal damage. The term malignant hypertension is usually reserved for cases where papilloedema is present.

Where there is no evidence of target organ damage, the condition is a hypertensive 'urgency' rather than 'emergency' and treatment may be more gradual.

Finding accelerated hypertension or malignant hypertension in a patient demands urgent admission for assessment and treatment to lower blood pressure within hours in order to minimize further end-organ damage and reduce the risk of life-threatening events such as myocardial infarction, encephalopathy and intra cerebral or subarachnoid hemorrhage.

\section{Clinical Presentation}

A 42 years old Indian male presented with more than 2 months history of generalized weakness with dizziness, swelling of feet and blurring of vision. There was no association of chest pain ,palpitation, blackout ,speech impairment or any decreased or burning micturation.

$\mathrm{He}$ is of average socio-economic status with normal bowel and bladder habit. He is a known case of hypertensive disorder for last 1 year and was treated with telmisartan 10mg daily, but he admits of not been keen in taking the medication and therefore he was not adherent to therapy or follow-up.

He had a strong family history of hypertension, both parents had hypertension and his mother had history of diabetes .He does a 8-9 hour standing job and rarely does exercise. He is a chronic alcoholic for 20 years ,having an average drinking habit of $350 \mathrm{ml}$ of liquor per day.

On examination he was conscious, alert and well oriented to time ,place and person .He looked well with BMI of $26.3 \mathrm{~kg} / \mathrm{m}^{2}$, his BP was 210/110 $\mathrm{mmHg}$ in supine position with pulse of $104 / \mathrm{min}$ regular ,good volume and character with no radio-radial delay or radio-femoral delay. There was bilateral pitting edema in both lower limb. In fundoscopy showed grade 4 changes with hard exudates.

There was no clinical evidence of cardiac failure, rest of the physiological changes where normal ,with no notable neurological signs. 


\section{Investigation}

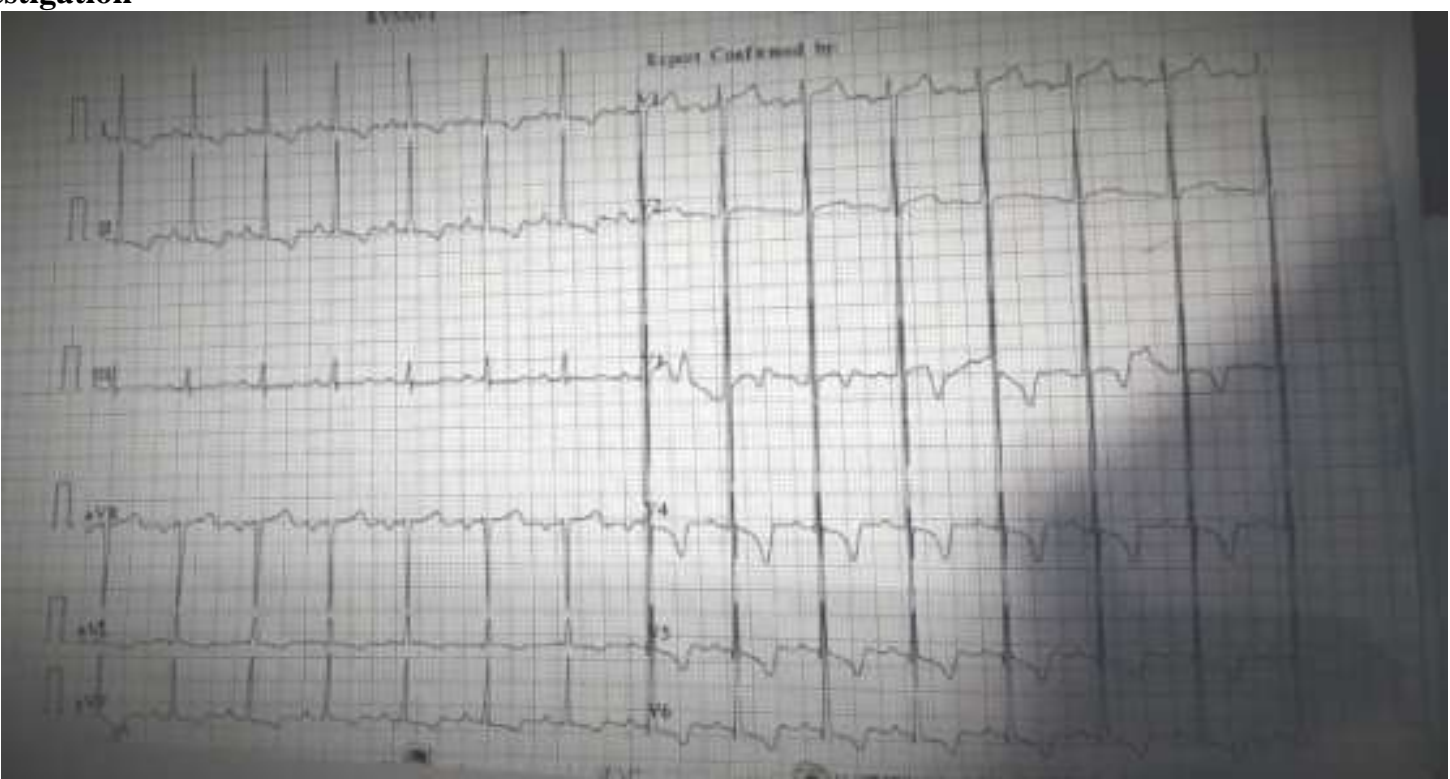

Fig 1:-ECG of the patient

Rest ECG shows presence of left ventricular hypertrophy, Inverted T wave at V4, V5 and V6 , and Deep negative wave at V4.

\begin{tabular}{|l|l|l|}
\hline Test & value & Reference value \\
\hline WBC & 10.3 & $4-10 \times 10^{3} / \mathrm{uL}$ \\
\hline RBC & 4.307 & $4.5-5.5 \times 10^{6} / \mathrm{uL}$ \\
\hline Hemoglobin & 8.98 & $13-17 \mathrm{gm} / \mathrm{dl}$ \\
\hline MCV & 69.78 & $83-101 \mathrm{fL}$ \\
\hline MCH & 20.86 & $27-32 \mathrm{pg}$ \\
\hline MCHC & 29.9 & $31.5-34.5 \mathrm{~g} / \mathrm{dl}$ \\
\hline PLATELET & 180 & $150-410 \times 10^{3} / \mathrm{uL}$ \\
\hline Serum .Iron & 65.3 & $65-175 \mathrm{microgm} / \mathrm{dl}$ \\
\hline Ferritin & 228.3 & $30-250 \mathrm{ng} / \mathrm{ml}$ \\
\hline S.TIBC & 285.6 & $250-450 \mathrm{microgm} / \mathrm{dl}$ \\
\hline
\end{tabular}

TABLE 1-CBC AND IRON PROFILE

Hematology report shows microcytic hypochromic anemia with decreased MCV (69.78fL) and MCH(20.86 pg) value with normal iron profile .

\begin{tabular}{|l|l|l|l|}
\hline TEST & On Admission day & On Discharge day & Reference Value \\
\hline S. Albumin & 4.7 & & $3.5-5.2 \mathrm{gm} / \mathrm{d}$ \\
\hline S. Globulin & 3.0 & & $2.0-3.8 \mathrm{gm} / \mathrm{dl}$ \\
\hline A/G ratio & 1.6 & & \\
\hline S. Sodium & 128 & 137 & $135-145 \mathrm{gm} / \mathrm{dl}$ \\
\hline S. Potassium & 3 & 3.8 & $3.5-5 \mathrm{gm} / \mathrm{dl}$ \\
\hline S. Creatinine & 2.88 & 3.17 & $0.9-1.3 \mathrm{gm} / \mathrm{dl}$ \\
\hline S. Urea & 73 & & $12-42$ \\
\hline S. Uric Acid & & & $3.5-7.2 \mathrm{mg} / \mathrm{dl}$ \\
\hline S. Calcium & & & $8.6-10.2 \mathrm{mg} / \mathrm{dl}$ \\
\hline S. Phosphorous & & & $2.5-4.5 \mathrm{mg} / \mathrm{dl}$ \\
\hline FBS & 123 & 90 & $70-100$ \\
\hline
\end{tabular}

TABLE 2- Serum report

Serum profile initally shows hyponatremia-hypo kalemia with increased creatine levels suggesting kidney damage, which later showed improvement in serum sodium, serum potassium and serum creatine. 
Case Study On Accelerated Hypertension With Grade IV Retinopathy And Nephropathy

\begin{tabular}{|l|l|}
\hline COMPONENT & On admission day \\
\hline Protein & Present $(4+)$ \\
\hline Sugar & Absent \\
\hline Pus cell & Nil \\
\hline RBC & Nil \\
\hline Cast & Nil \\
\hline Crystal & Nil \\
\hline
\end{tabular}

TABLE 3- Urine report

Urine routine microscopic report shows no infection or hematuria, but presence of proteinuria. Suggesting kidney disease.

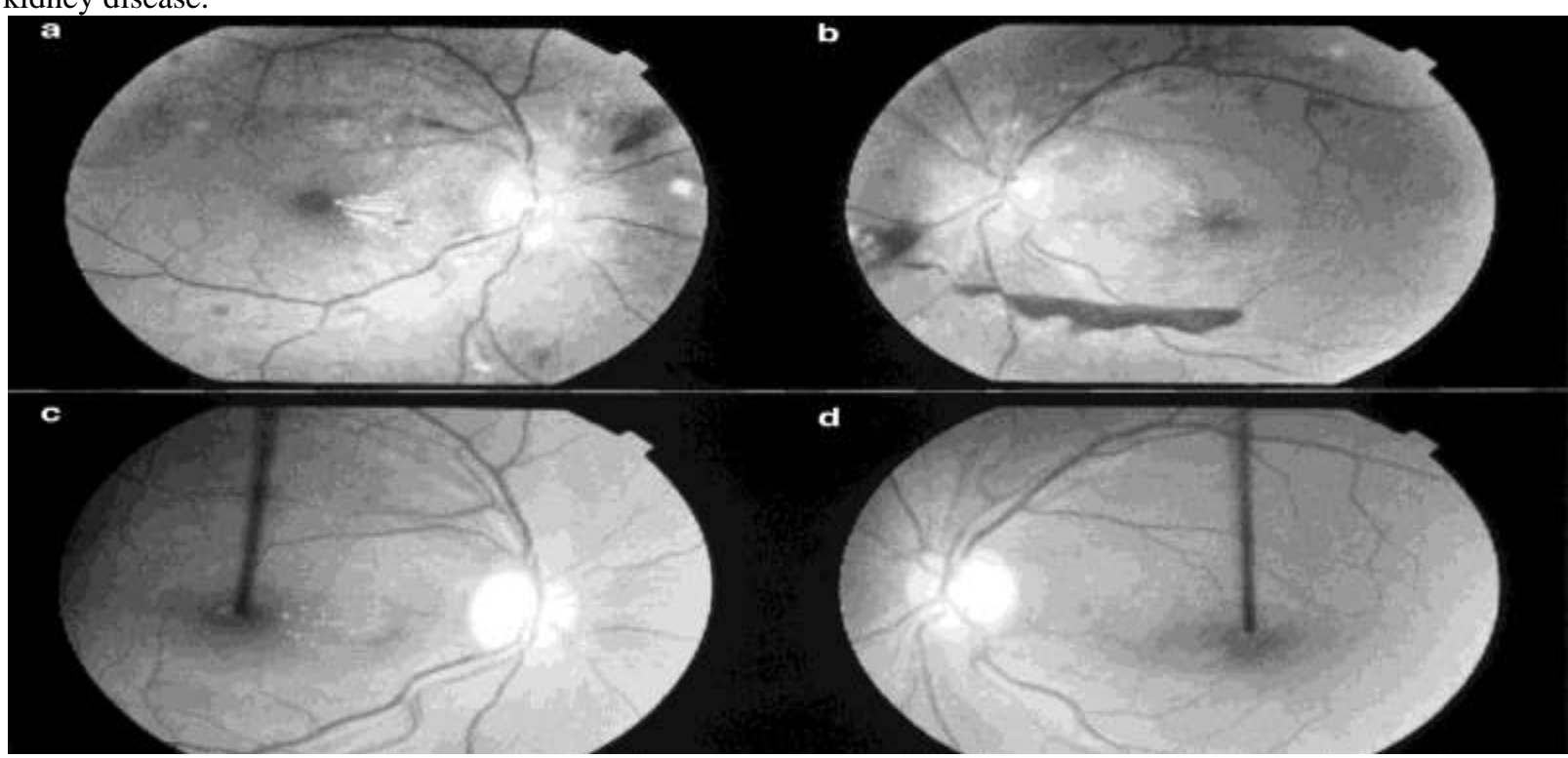

Fig2-fundoscopy picture of both eyes

Fundoscopy of both the eyes reveals bilateral papilloedema with presence of hard exudates

\section{Diagnosis}

Poorly controlled accelerated hypertension with left ventricular hypertrophy and grade IV retinopathy and nephropathy.

\section{Management}

He was admitted to the hospital for optimizing his hypertensive management and also because the admitting resident medical officer was worried that he might be having any impending hypertensive emergency such as stroke.

Initially to lower his blood pressure he was given -

○ Injection lobert 1 amp iv stat

○ Tablet nifidipine (20mg) thrice daily

- Tablet dytar(5mg) 1 tab once daily

With orders to monitor his BP, pulse and input-output closely.

\section{Progress}

Over the next 24 hours his BP fell gradually to $184 / 100 \mathrm{mmHg}$. There was neither any episodes of uneasiness in chest nor he developed any neurological deficit. Over the next 4 hours his BP lowered around $160 / 100 \mathrm{mmHg}$ with pulse rate $94 / \mathrm{min}$.

$\mathrm{He}$ was advised to do a 2D-echo, renal function test ,renal artery Doppler study a nephrology consultation to check any nephrology damage due hypertension .2D-echo revealed $61 \%$ ejection fraction with dilated left atrium and grade II diastolic dysfunction. Renal artery Doppler study showed no stenosis with grade II bilateral renal disease and left simple renal cysts, the cortico-medullary differentiation was diminished in both the kidneys .

Serum creatinine was $3.14 \mathrm{mg} / \mathrm{dL}$ and Serum Sodium was $137 \mathrm{mg} / \mathrm{dL}$, rest of the reports were within normal limits.

As his Bp was still high, his medication was improvised to

○ Tab NIFIDIPINE (20) 1 tab Twice Daily 
- Tab CLONIDINE(100microgram) 1 tab Thrice Daily

- Tab METOPROLOL(50) 2tab Once Daily

- Tab PRAZOSINE (2.5) 2tab Once Daily

- Tab TORSEMIDE (10) 1 tab Once Daily

- Tab ROSUVASTATIN(10) 1tab Once Daily

To prevent further kidney damage he was advised -

- TAB ALPHA KETOANALOGUE 1 tab Thrice Daily

To improve his hemoglobin level, he was advised-

○ INJ ERYTHROPOIETIN(4000 IU)S/C WEEKLY for 3 weeks

He was discharged symptoms free at day 5 with ambulatory BP-150/90mmHg.he was asked to continue his medication deliriously to come for follow up after 2 weeks. After 2 weeks his BP was $140 / 84 \mathrm{mmHg}$ there was no further deteriorate in his state .So there was no change in his medication and was asked to come for follow up after 2 months.

\section{Conclusion}

This case in the setting of sudden rise of blood pressure with end organ damage is example of accelerated hypertension and its treatment to it, without treatment, accelerated hypertension may result in death within a year in over $90 \%$ of patients as a result of end-organ damage - e.g., myocardial infarction, CVE or renal failure. The prognosis has improved dramatically over the period of a few decades and with optimal treatment the five-year survival rate is $>80 \%$.So if accelerated hypertension is treated in time ,then emergency condition can be avoided.

\section{Acknowledgement}

The author is grateful to Dr.G.C.Mishra ,Medicine Director of Kalinga Institute of Medical Sciences and Dr A.P. Mohanty HOD Medicine ,Kalinga Institute of Medical Sciences for kind permission and ,encouragement. She is grateful to the faculty of Medicine department, Kalinga Institute of Medical Sciences for their support to publish this paper.

\section{References}

[1]. Weinstein MC, Stason WB. Hypertension, a policy perspective. Cambridge: Harvard University Press, 1976.210

[2]. van Zee BE, Hoy WE, Tally T, Jaenike JR. Renal injury associated with intravenous pyelography in nondiabetic and diabetic patients. Ann Intern Med !978;89:51-54

[3]. Kasper DL, Braunwald E, Fauci A, Hauser S, Longo D, Jameson JL. Harrison's Principles of Internal Medicine, 19th edition. New York: McGraw-Hill Medical Publishing Division, 2005.

[4]. Shantsila A, Shantsila E, Lip GY; Malignant hypertension: a rare problem or is it underdiagnosed? Curr Vasc Pharmacol. 2010 Nov;8(6):775-9.

[5]. Hypertension: management of hypertension in adults in primary care; NICE Clinical Guideline (August 2011)

[6]. Blumenfeld JD, Laragh JH; Management of hypertensive crises: the scientific basis for treatment decisions. Am J Hypertens. 2001 Nov;14(11 Pt 1):1154-67.

[7]. Williams B, Poulter NR, Brown MJ, et al; British Hypertension Society guidelines for hypertension management 2004 (BHS-IV): summary. BMJ. 2004 Mar 13;328(7440):634-40.

[8]. van den Bogaard B, Immink RV, Westerhof BE, et al; Central versus peripheral blood pressure in malignant hypertension; effects of antihypertensive treatment. Am J Hypertens. 2013 Apr;26(4):574-9. doi: 10.1093/ajh/hps075. Epub 2013 Jan 10.

[9]. Lane DA, Lip GY, Beevers DG; Improving survival of malignant hypertension patients over 40 years. Am J Hypertens. 2009 Nov;22(11):1199-204. doi: 10.1038/ajh.2009.153. Epub 2009 Aug 20.

[10]. Task Force Members, Montalescot G, Sechtem U, et al. ESC guidelines on the management of stable coronary artery disease. Eur Heart J 2013; 34:2949-3003.5

[11]. Task Force Members, Mancia G, Fagard R, et al. 2013 ESH/ESC Guidelines for the management of arterial hypertension: The Task Force for the management of arterial hypertension of the European Society of Hypertension (ESH) and of the European Society of Cardiology (ESC). Eur Heart J 2013; 34:2159-2219

[12]. Staessen JA, Wang JG, Thijs L. Cardiovascular protection and blood pressure reduction: a meta-analysis. Lancet 2001; 358:13051315. 